\title{
PD05 - Asthma and allergy from infancy into school age - the allergic march revisited
}

Emma Goksör, Bernt Alm, Rolf Pettersson, Per Möllborg, Laslo Erdes, Petra Loid, Nils Åberg, Göran Wennergren

From 3rd Pediatric Allergy and Asthma Meeting (PAAM)

Athens, Greece. 17-19 October 2013

\section{Background}

The allergic march describes a proposed natural course of allergic disease during childhood. However, different patterns of allergic morbidity have been suggested. The aim of this study was to describe the prevalence of doctordiagnosed asthma and allergic manifestations from infancy into school age and the relationship between early manifestations and the prevalence of asthma at school age.

\section{Methods}

Data were obtained from a prospective, longitudinal study of a cohort of children born in western Sweden. The parents answered questionnaires at 6 months and 1 , 4.5 and 8 years of age. The response rate at 8 years was
$80 \%$ of the questionnaires distributed $(4,051 / 5,044)$, that is $71 \%$ of the families entering the study $(4,051 / 5,654)$.

\section{Results}

The prevalence of recurrent wheeze decreased from infancy to school age (5,4\% to $3,4 \%)$, but the prevalence of doctor-diagnosed asthma increased from $2,1 \%$ in infancy to $5,7 \%$ at 8 years of age. The prevalence of doctor-diagnosed eczema was more than halved from infancy to school age $(20.9 \%, 8.6 \%$ and $7.9 \%$ at age 1,4 and 8 years, respectively), while doctor-diagnosed food allergy decreased slightly (4.9\%, $2.8 \%$ and $3.5 \%)$. Doctor-diagnosed rhinitis increased from $1.7 \%$ at age 4 to $5.6 \%$ at age 8 years.

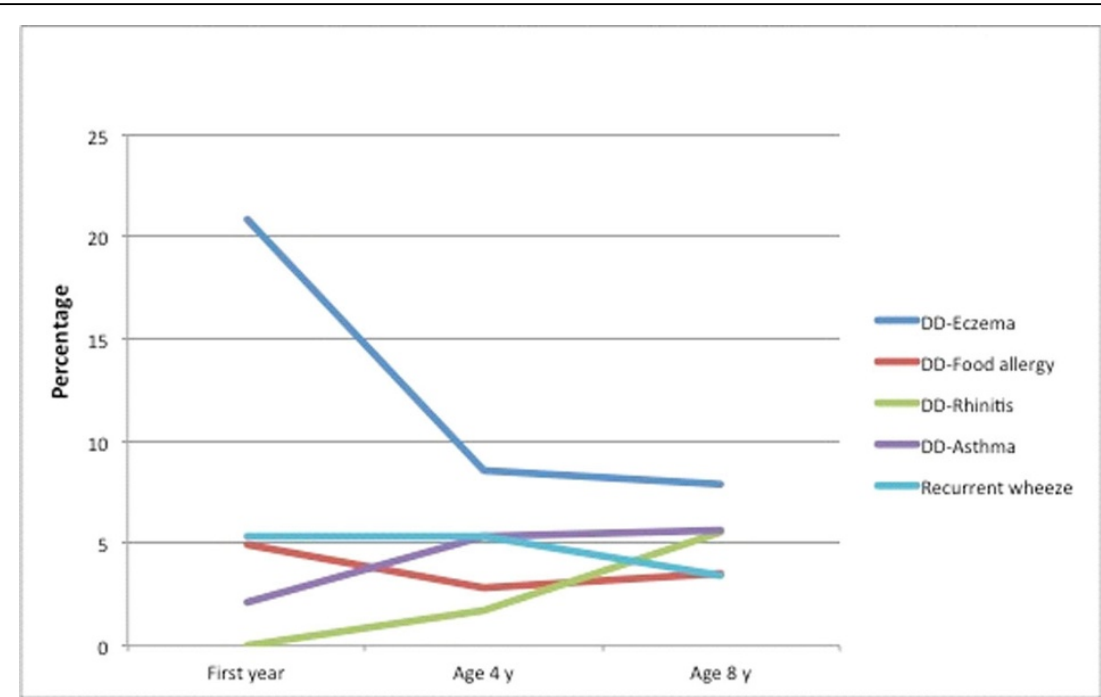

Figure 1 Prevalence of doctor-diagnosed allergic manifestations, doctor-diagnosed asthma and recurrent wheeze during childhood in the cohort.

Department of Pediatrics, University of Gothenburg, Gothenburg, Sweden 


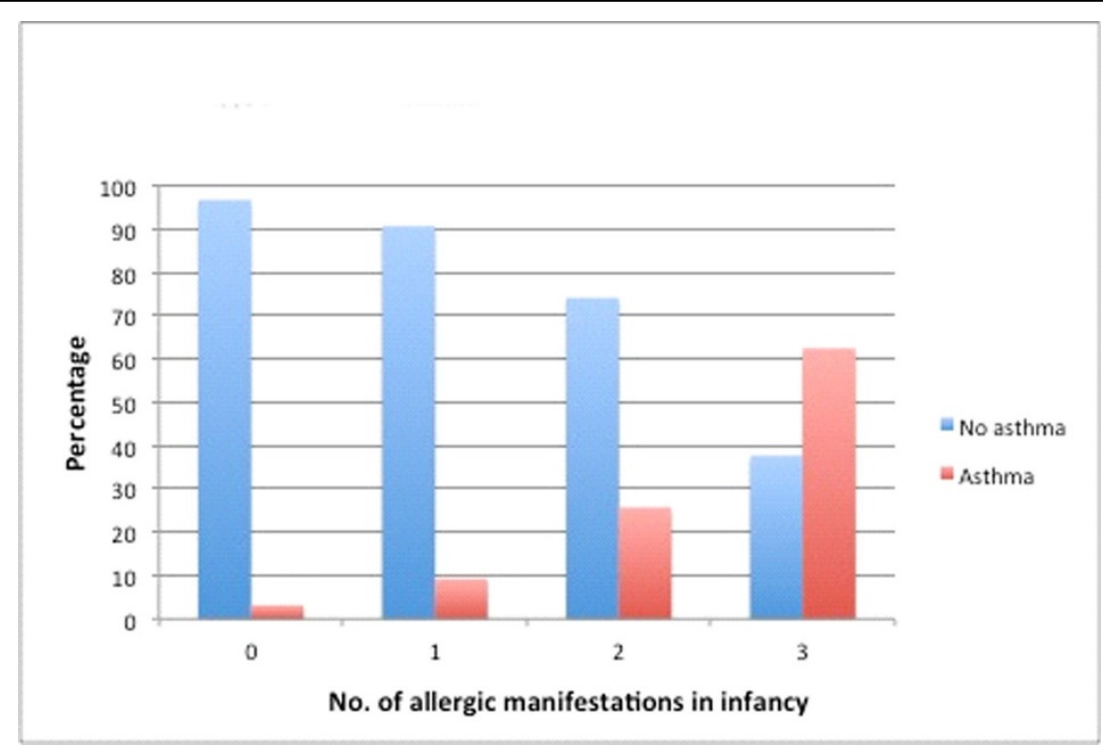

Figure 2 Prevalence of doctor-diagnosed asthma at age 8 years among subjects with 0 to 3 manifestations, i.e. doctor-diagnosed eczema, food allergy or ICS-treated-wheeze in infancy

The prevalence of school age asthma increased with the number of allergic manifestations that was seen during infancy. Of those with 3 early manifestations (eczema, food allergy and wheeze treated with inhaled corticosteroids) more than $60 \%$ had doctor-diagnosed asthma at 8 years, compared with only $3 \%$ school age asthma among those who were symptom-free in infancy.

\section{Conclusion}

Doctor-diagnosed asthma and rhinitis increase, while eczema and food allergy decrease from infancy into school age in line with the proposed allergic march. In children with several early allergic manifestations in infancy two out of three have doctor-diagnosed asthma at age 8.

Published: 28 February 2014

doi:10.1186/2045-7022-4-S1-P5

Cite this article as: Goksör et al:: PD05 - Asthma and allergy from

infancy into school age - the allergic march revisited. Clinical and

Translational Allergy 2014 4(Suppl 1):P5.
Submit your next manuscript to BioMed Central and take full advantage of:

- Convenient online submission

- Thorough peer review

- No space constraints or color figure charges

- Immediate publication on acceptance

- Inclusion in PubMed, CAS, Scopus and Google Scholar

- Research which is freely available for redistribution

Submit your manuscript at www.biomedcentral.com/submit 